\title{
Comparative study on the internationalization propagation mode of competitive martial and taekwondo
}

\author{
Liu Qi ${ }^{1, a}$ \\ ${ }^{1}$ Chengdu sports university, 610000 \\ a13888660333@139.COM
}

Keywords: Competitive Chinese martial; Taekwondo; internationalization; communication mode

\begin{abstract}
All the time, competitive Chinese martial is the dream for the Olympic Games, but this dream has not been realized. As the representative of excellent traditional culture of the Chinese nation, it has not taken as the game project of Olympic Games like South Korea Taekwondo. It is not a pity. In regret at the same time, we should think this gap deeply. In this paper, this phenomenon is taken as the basis, firstly, the development process of the both projects are analyzed and compared, based on the logic of history, The international communication patter of the two events are compared, related suggestions are proposed as the references of related departments.
\end{abstract}

\section{Introduction}

Chinese martial has always been taken as a representative of the Chinese outstanding culture, and the competitive Chinese martial is typical of the Chinese martial. During the development history for thousands of years, the Chinese martial is constantly sucking and integrating various culture, and gradually formed unique culture with national characteristics. The development of Chinese martial has experienced vicissitudes, the initial Competitive Chinese martial is to defend the territory, and serve the country, now is to inherit civilization, martial arts works for the international communication of Chinese culture with our own contribution. Science and technology of current is changing rapidly, under the impact of globalization, culture of east and west is colliding and fusing, Chinese martial as the representative of the traditional culture is facing great opportunities and challenges. However, the international spread of Competitive Chinese martial is not as fast as Korean taekwondo. Both of them belong to Eastern Wu Dao, and Taekwondo inferiors to martial at the historical origin, cultural connotation and other aspects, but it can be spreading in a short span of forty or fifty years, eventually become the official Olympic Games in 2000, and won the "world's first combat movement" reputation, Chinese martial didn't get close to the Olympics as Taekwondo, only listed as a spectator sport. From the huge contrast it can be seen that, in the international promotion, Taekwondo has been walking in the front of competitive Chinese martial. Now, there are a lot of Taekwondo places in China, and Chinese martial slowly fade out from people's eyes, the living space of martial is gradually squeezed. Therefore, through the comparative study of Competitive Chinese martial and Taekwondo international communication mode, referring to the comparison, and find international communication mode suitable for the Chinese martial, so as to carry forward the Chinese martial, has the important practical significance.

\section{A review of international propagation process of Competitive Chinese martial}

Chinese martial has a long history, broad and profound. After the People's Republic of China was founded, the party and the country attached great importance to the development of Chinese martial, the National Sports Commission set up special boards for sports of national form in 1952, and Chinese martial is one of the research objectives. Countries held national martial competitions in order to promote Chinese martial. For example, in 1953 Tianjin held the first national sports show and competition of national forms, in 1954 the National Sports Commission established the first National Chinese martial team, and established a Martial Arts Section for Chinese martial at second year, and upgraded to the Martial Arts Division, directly under the sports department. Chinese martial Association was founded at Beijing in 1958, so far martial arts association established everywhere, and gradually formed a complete Chinese martial organization. The State 
Sports Commission introduced competition system of martial in 1959, from then Chinese martial stepped into the development of high-speed. However, ten years of the Cultural Revolution caused great harm to the development of martial, and become a catastrophe on the history of the development of Chinese martial. After the reform and open, the first national martial arts work conference held at Beijing in 1982, pointed out the direction of Chinese martial in the new era. Sports Department of National Sports Commission set up Chinese martial Sanshou research group in 1978, belongs to the martial division, thus, the Chinese martial Sanshou is developing. In 1987, various martial, martial school, martial club in the domestic has exceeded a million. In 1987, Chinese martial was officially listed as an official event in the Sixth National Games, in the 1990, Chinese martial was listed as an official event in Beijing Asian Games. After that, the competitive Chinese martial is developing along two lines, routines and Sanshou, "Chinese martial Duan system" issued and implemented in 1997. These measures greatly encouraged people to participate in the martial, expanded the influence and popularity. At the same time, the martial was also regarded as one of the school physical education teaching content, as a representative of the national traditional sports.

The history of international communication of Chinese Martial dates back to ancient time. After the founding of the People's Republic of China, it has been out of the country. In 1960 Chinese youth martial team visited Czechoslovakia, and visited Burma with Premier Zhou. Subsequently, they had tour among various countries, expanded the influence of Chinese martial in the overseas. The International Chinese martial Federation became a member in the international single sports federations in 1994, henceforth once World Chinese martial championships is held every two years. And Chinese martial was selected as the formal event in Hiroshima Asian Games (1994) and Bangkok Asian Games (1998). The International Chinese martial Federation currently has members from more than 120 countries and regions. After 1990, Chinese martial routines become official competition projects in many comprehensive sports games, such as the Asian Games, South Asian Games, and Southeast Asian games. Olympic Committee admitted the International Chinese martial Federation in 1999 , after Beijing's successful Olympic bid, China have been seeking competitive Chinese martial's bid, but failed to be added into the column, just as ornamental game, but it's enough to make spreads' goal of Chinese martial closer.

\section{A review of international spread course of South Korea Taekwondo}

South Korea as one of the most developed Asian countries, Taekwondo's development is quite similar to development of economy, according to historical records, from the end of 1950, South Korean Taekwondo began to expand internationally, and the Chinese Martial Arts Internationalization promotion is about the same time, which means that they are in the same starting line. The International Taekwondo Federation represented by Cui Hongxi made an outstanding contribution to the promotion of the taekwondo internationally. They adopted modern marketing methods, started from 1958 to have the first performance tour in Southeast Asia area, and then sent a popularity of Taekwondo coaches in these regions designedly. After the war occurred in Vietnam, they sent a delegation of coaches and performance to South Vietnam to display charm of Taekwondo for the soldiers, after the end of the Vietnam War, these soldiers returned home and brought the influence of Taekwondo to the world, prepared for the further communication. In the 70's of last century, South Korea reorganized and merged the diverse Taekwondo factions, and set up the research institutions-Korea Taekwondo state technical institute. The establishment of this institution means that the Korea Taekwondo is institutionalized officially, unified and perfected technical theory system of Taekwondo, formulated the relevant rules of the game and the standard of evaluation and management strategy, and has laid a good foundation for the next step of development. Korea Institute of technology has become the World Taekwondo authority organization, Kukkiwon held the first World Taekwondo Championships in 1973. The World Taekwondo Federation was founded in the same year, held the Taekwondo competition in various countries after that, and the World Taekwondo Federation was recognized by International Olympic 
Committee in 1980, 19 years earlier than International Chinese martial Federation acknowledged by the IOC. Since then, South Korea Taekwondo have an all-round development, selected as a demonstration project in two session of Olympic Games 1988 and 1992, elected to be competition project in the 2000 Sydney Olympic Games successfully, which means South Korean Taekwondo international communication has achieved victory at current stage. WTF now has 182 memberships, the development potential is very rapid.

\section{Comparison of competitive Chinese martial and Taekwondo internationalization mode}

In the course of analysis for Competitive Chinese martial and Taekwondo international communication can be seen, the propagation pattern of them have some similarities, also has distinctive points. The author, on the basis of analysis, make the comparative analysis for communication pattern from three aspects, the structure of communication organization, communication content and communication strategies.

\section{A.Comparison of propagation organization of Competitive Chinese martial and Taekwondo}

Propagation organizations competitive martial in China mainly includes Chinese martial management center, Chinese martial Research Institute, Chinese martial Association and the International Chinese martial federation. The Chinese martial Association was founded in 1956, it is the group member of all China Sports Federation and Olympic Committee of China. Chinese martial Research Institute established in 1986, began to study Chinese martial systematically. In 1990, the International Chinese martial Federation founded, now already be recognized by IOC officially. Chinese martial management center established in 1994, is the permanent office of Chinese martial association. Propagation organization of South Korea Taekwondo mainly includes the Kukkiwon the World Taekwondo Federation, the International taekwondo. The agency is not as many as competitive Chinese martial, and the establishment time is later than propagation organizations of Chinese martial, such as the International Taekwondo Federation was founded in 1966, this is the first international organization in Korea; then the Kukkiwon established in 1972, has become the center and the authority of World Taekwondo; the World Taekwondo Federation (WTF) founded in 1973, more than 190 members. These institutions were established in order to manage the Chinese martial project better, which is same to South Korean Taekwondo, so communication organization established for the similar purpose, but have different contribution for the propagation of countries. The organization of Chinese martial is more official, and the promotion mode is top-down, while South Korea's organization is more democratic, encourage market to perform function, although the purpose is the same, but different in nature.

\section{B.Comparison of propagation content of Competitive Chinese martial and Taekwondo}

During the development process of Competitive Chinese martial and Taekwondo respectively, both of them have their own development model, but all of them are absorbing and fusing excellent culture from various national groups constantly, and exhibit a high degree of similarity for the traditional etiquette. For example, there are some requirements in Chinese martial, "Be humble before learning martial ", "start and end with etiquette" is a taekwondo requirement, and we can see the attention for etiquette clearly. Although Competitive Chinese martial and Taekwondo etiquette is relatively similar, they are different, the etiquette of competitive Chinese martial is to rely on the "practice", and etiquette of Taekwondo is rely on "learning". Connotation is different, Competitive Chinese martial emphasized on routines, which combing the offensive and defensive, static and movement. Taekwondo focus on character, also known as the "type", the defense and attack moves are combined into a particular routine to practice. There is another type of Competitive Chinese martial named Sanda, in ancient times is called hand fighting, which is more similar to Taekwondo. In addition, rules of competitive Chinese martial and Taekwondo is quite distinctive, which makes Taekwondo more conducive during process of communication by the simple rules, the evaluation 
standards of martial are not unified, while Taekwondo has formed a unified standard of evaluation, which is not conducive to the internationalization of Chinese martial.

\section{C.Comparison of communication strategy of Competitive Chinese martial and Taekwondo}

The international spread of Competitive Chinese martial and Taekwondo are actually received strong support from the government, but the only difference is that, China attaches great importance to the martial, but the emphasis is not as strong as Korea. For Chinese martial, the state only establish institutions, researching and learning Chinese martial, and teach some basic routines to primary and middle school students in physical education, however, among the entire national ideology, the martial is not regarded seriously. South Korea is quite different, Taekwondo has been given a high social status, also was revered as "national martial arts". Taekwondo is not only the Korean nation traditional sports, also be regarded as symbol of South Korea's outstanding cultural and spiritual strength. In addition, South Korea also attaches great importance to the communication effect of school. South Korean government believes that every adult students come from school, and current students will enter into the society, so what they learn in school is very important for their days later. South Korean government makes use of this point, Taekwondo regarded as a compulsory course as physical education for elementary and secondary students, and also arranged a number of class for students to introduce basic knowledge and action of Taekwondo, also held University Taekwondo competition, which greatly promoted the spread of Taekwondo in the university. Communication in school strategy makes Taekwondo has a long-term, stable propagation object in Korea, thus maintain the consistency of communication, laying a good foundation for the international spread of South Korean Taekwondo. In contrast, Chinese martial arts is lack of strong supporting, although the government also introduce martial into class, but the degree is weak, many schools are under the pressure of entering a better school, and ignore the class, and also did not count Chinese martial curriculum as a compulsory course, thus, many students contact to Chinese martial rarely, let alone interests, which leads to failure on implementation of good policy of the government eventually, and also affect the future communication of Chinese martial internationally, makes Chinese martial lacking of long-term stable communication object, which is not conducive to long-term development.

\section{Conclusions and suggestions}

In the aspect of communication organization, our country established Chinese martial Association, sports management center, Martial Arts Research Institute, the International Chinese martial Federation and other institutions. South Korea established Taekwondo State Technical Institute, the World Taekwondo federation. There are many similar places of these organization, but the organization of Taekwondo have bigger influence in the world. In the communication content, as for etiquette, Chinese martial etiquette comes from "practice", and Taekwondo etiquette comes from "learning". Chinese martial is rich in content, but the difficulty is relatively large, so it is not easy to master in short time. While movements of Taekwondo is easy and quick to be picked up by public and popularity. As for communication strategies, through the comparison of national policy support of Chinese martial and Taekwondo, which South Korea make good use of school platform to benefit spreading of Taekwondo, while because of the long-term influence of college entrance examination in China, this communication pathway did not play the role. Setting of stadium and coaches training and so on, all are the key impact. Based on these conclusions, the author puts forward the following three suggestions for related departments to refer.

First of all, reshaping the "country technique" status of martial. In the promotion of martial, not just regard as a simple sports promotion, more important is the promotion of martial arts culture connotation, to enhance the attractiveness of Chinese martial. The second is to balance the competitive with traditional, in the meanwhile to inherit and carry forward the traditional Chinese martial essence, also should actively absorb the outstanding achievements of modern competitive sports, combining fight and practice of the athletics martial together, forming a fighting system with 
national characteristics. Then, Chinese martial competition system should be simplified and unified. It can be seen from the international spread of South Korean Taekwondo, it is very important to formulate evaluation criteria, which can perfect the theory system of the project, unify the standard. Therefore, based on perfecting the theory system of martial, unify all aspects of the standard of the martial, to show the charm of Chinese martial to the public. Then, we should reform and improve the existing class appraisal system, combining exercises and actual combat to set class appraisal reasonably, so as to motivate practitioner learning continuously. Then, creating the brand of martial. During the promotion of the martial, combining the fashion, especially some fashion elements and some clothing, will make the Chinese martial arts brand. Finally, performance groups should be sent to other countries for touring designedly, starts propagation step by step, with the use of Confucius college to packing Competitive Chinese martial, to lay a good foundation for the internationalization of Chinese martial.

\section{References:}

[1] Textbook for national institutes of physical education. Theoretical basis of martial art [M]. Beijing: Peoples Sports Publishing House, 1997.

[2] Liu Jianguo. Development ideas and countermeasure study of traditional martial art [J].3 40-342.

[3] Zhang Haibin. On the Enlightment from Development of Taekwon - Do in South Korea [J]. Journal of PLA Institute of physical education, 2002, (2):71-73.

[4] Ma Bo. Enlightenment of development of Taekwondo to Chinese Wushu [J]. Journal of sports adult education, 2006,(1):23-24. 